\title{
Riso: uma solução intermediária para os racistas no Brasil
}

\section{Laugh: an intermediate solution for racists in Brazil}

\section{Sandra Leal de Melo Dahia}

Professora Adjunta do Departamento de Psicologia da Universidade Federal do Amazonas - UFAM, Manaus, AM, Brasil

\begin{abstract}
RESUMO
O objetivo do presente trabalho consiste em considerar o riso como uma forma expressiva de transmissão e manutenção do preconceito racial contra o negro no Brasil. O riso é manifesto como reverberação do relato da piada racista em espaços sociais de lazer nos quais os grupos liberam e partilham seu racismo encoberto. Consideramos que se trata de uma prática social, negociada inconscientemente, cuja principal função está em lidar com o dilema de identidade do brasileiro frente à melindrosa questão das relações raciais no país. Utilizaremos como suporte teórico os conceitos de aliança inconsciente e transmissão psíquica e a categoria do intermediário, oriundas da teoria psicanalítica do francês René Kaës que parece penetrar as realidades dos pactos intersubjetivos selados inconscientemente. A leitura proposta atesta a interface entre inconsciente e cultura, apontando um dinâmico e criativo processo de construção e desconstrução de soluções intermediárias de defesa, coletivamente produzidas e articuladas.
\end{abstract}

Palavras-chave: Riso, Piada racista, Racismo, Aliança inconsciente, Categoria intermediária.

\begin{abstract}
The aim of the present work is to consider the laugh as an expressive way of transmitting and maintaining the racial prejudice against the black in Brazil. The laugh is manifested as a reverberation of the racist joke at social leisurely spaces where members release and share their covert racism. We consider that this represents a social practice that has been negotiated unconsciously and whose main function is to deal with the identity dilemma faced by the Brazilians with regard to the delicate issue of racial relations in the country. We use as theoretical support the concepts of unconscious alliances and psychic transmission and the intermediate category, all derived from the French psychoanalytic theorist René Kaës. These concepts seem to reach and penetrate the realities of the inter-subjective agreements sealed unconsciously. Our proposed reading attests to the interface between the unconscious and culture pointing to a dynamic and creative construction-deconstruction process of intermediate defensive solutions collectively produced and articulated.
\end{abstract}

Keywords: Laugh, Joke, Racism, Unconscious alliance, Intermediate category. 


\section{I ntrodução}

O presente artigo visa fornecer uma leitura para a compreensão do riso como um elemento fundamental para transmissão e manutenção do preconceito racial contra o negro no Brasil. Para isso, tenta inscrever o riso no foco de uma análise que conduz aos meandros da atuação intersubjetiva do inconsciente e ressignifica seu papel na história do nosso racismo. O riso, o deboche, o jeitinho brasileiro, ou seja, o modelo ambíguo selecionado para expressar o preconceito racial contra - negro no Brasil, parece remeter a uma lógica própria ao universo inconsciente. Ao que parece, esta suposição se refere a um grande número de brasileiros. Não estamos lidando com os indivíduos que adotam uma atitude conscientemente encobridora do preconceito, em consequência do temor à lei. Nos referimos, somente, àqueles que se percebem como democratas raciais e procuram adotar uma postura "politicamente correta", no tocante às relações raciais, por considerá-la moralmente certa. No entanto, quando, num ambiente social, são instados a contar piadas racistas, ou delas rir, destilam seu preconceito sem nenhum constrangimento. Um vasto número de pesquisas corrobora essa ambiguidade dos brasileiros frente à questão racial. (CAMINO; SILVA; MACHADO; PEREIRA, 2001; PEREIRA; TORRES; ALMEIDA, 2003; além de outras).

De um modo geral, a manifestação encoberta do preconceito emerge no momento em que normas proibitivas em relação à discriminação contra grupos minoritários são instituídas. A instituição dessas normas acarreta todo um procedimento de sofisticação nos mecanismos de expressão do preconceito. Vários estudos recentes vêm apontando a existência desse fenômeno, em diferentes partes do mundo, como consequência de uma diminuição das formas abertas de discriminação racial (VALA, 1999; etc.).

Certamente, esta não é a razão principal da origem do racismo à brasileira, mais intimamente relacionado a outros condicionantes históricos e culturais, que remetem à própria construção da identidade nacional (DAHIA, 2007). Entretanto, na atualidade, as implicações da nova legislação (Lei n. 7716, de 05 de janeiro de 1989) sobre a questão racial vêm reforçando a cristalização do modelo sutil de racismo aqui vigente.

O eixo analítico sobre o qual nos fundamentamos aponta conceitos e categorias oriundos da teoria psicanalítica de grupo, de René Kaës (KAËS, 1997; KAËS; FAIMBERG; ENRIQUEZ; BARANES, 2001; KAËS, 2005). O objetivo dessa fundamentação teórica é o de conferir uma particular atenção a proposições inconscientes, que podem ser produzidas no espaço intersubjetivo. Em síntese, trata-se de procurar 
dar visibilidade a aspectos obscuros e sutis que jazem no estilo lúdico, empregado por alguns brasileiros, de ser racista. A teoria psicanalítica de Kaës permite introduzir conceitos como o de transmissão psíquica entre gerações e entre membros do grupo e o de alianças inconscientes, em articulação com categorias como intermediário e negativo, conferindo-Ihes uma interpretação singular. Desse modo, acreditamos poder vislumbrar, ainda que palidamente, uma nova perspectiva para pensar a dinâmica dos grupos frente às relações raciais.

\section{Riso: Uma solução intermediária para os racistas no Brasil}

O processo de socialização da criança brasileira indica a aprendizagem, desde cedo, de códigos sociais de disciplinamento e autodisciplinamento nas relações entre negros e brancos. Além disso, aponta para a institucionalização de canais e espaços sociais nos quais tais regras sociais não se aplicam, ou pelo menos, não se aplicam com o mesmo rigor.

Em contextos familiares, nas escolas e em outras situações sociais, a "etiqueta racial" vai se enraizando e se consolidando nas relações, de modo a transformar-se numa norma de conduta. Essa norma de conduta vai regulando, de uma forma não-explícita, a adequação de um vocabulário racial nas conversações cotidianas.

Em sua obra, Tanto Preto Quanto Branco: estudo de relações raciais (1985), Oracy Nogueira menciona, apropriadamente, o ditado: “Em casa de enforcado, não se fala em corda", para retratar o modo de regulação informal que ocorre sobre o comportamento social dos indivíduos, frente às relações raciais no Brasil $(p .86,1985)$. O autor chama a atenção para o caráter elucidativo dos ditos populares, no sentido de fornecerem uma leitura penetrante de aspectos complexos das realidades culturais. Nogueira aborda essa questão no contexto da distinção estabelecida entre o preconceito racial de origem e o preconceito racial de marca, vigentes nos EUA e no Brasil, respectivamente.

De acordo com Nogueira (1985), entre os brasileiros brancos há uma preocupação com um autodisciplinamento do comportamento, no sentido de não ferir a suscetibilidade dos negros. A dinâmica dessa etiqueta social requer decoro e reserva sobre temas de caráter racial diante de indivíduos negros, salvo nos casos de conflitos, quando o controle é relaxado e a cor do indivíduo é prontamente evocada.

Em tempos de paz, no entanto, o emprego do termo "negro", para designar indivíduos com características negróides, cede lugar para os eufemismos, como "moreno", "caboclo", etc. Não apenas os maneirismos na linguagem, mas o próprio silêncio sobre a questão racial 
como assunto tabu, refletem a opção cultural do brasileiro pelo caminho da conciliação e do não-enfrentamento de temas melindrosos.

Portanto, não é possível compreender o desenvolvimento do preconceito racial nas crianças sem levar em conta a significação e atribuição valorativa contidas nos discursos produzidos cotidianamente pelos adultos que as cercam, em relação às categorias raciais. Também não é possível compreender a perda da espontaneidade infantil, prenúncio de um tratamento aberto das questões raciais, sem a interferência de um rígido controle de comportamento, que prescreve todo um conjunto de procedimentos no jogo de ocultação/revelação da condição racial dos não-brancos no Brasil.

Contudo, a etiqueta racial não alcança todas as formas discursivas presentes na sociedade, nem todos os espaços sociais, pelo menos não com a mesma intensidade. Com efeito, existem espaços e discursos nos quais a expressão do preconceito racial não somente é socialmente consentida, mas, por vezes, até estimulada. É o que acontece, por exemplo, nos encontros sociais, que constituem um espaço de lazer onde as piadas racistas encontram vazão. ${ }^{1}$

Alguns dados empíricos fornecidos por pesquisas como, por exemplo, a realizada pela socióloga Rita de Cássia Fazzi, publicado no livro O drama racial de crianças brasileiras: socialização entre pares e preconceito (2004), indicam que não há uma inscrição negativa da piada, como algo nocivo e ofensivo. Enquanto em uma situação social rotineira e sem conflito assiste-se a uma interdição de temas que aludem diretamente à questão racial, bem como ao uso de termos considerados ofensivos, a piada dispensa qualquer acordo tácito de submissão normativa.

$\mathrm{Na}$ referida pesquisa, as crianças, objeto de sua análise, não consideraram a gozação racista ou a piada racista como um comportamento racial. Isto aconteceu mesmo com aquelas crianças que sofriam um rígido controle paterno quanto às relações raciais. Indagadas sobre 0 caráter racista de tais práticas, as crianças declaravam prontamente que se tratava de uma "brincadeira".

Essas práticas sociais, frequentes no processo de socialização, são toleradas e consideradas como uma atividade infantil inconsequente, que não deve ser levada a sério. ${ }^{2}$ Quando relacionada ao drama interracial em particular, demonstram constituir-se num mecanismo sutil, mas eficiente, de transmissão e perpetuação do preconceito racial. Ao longo da vida do indivíduo, tais práticas sociais acabam por se tornar um agradável hábito coletivo, atendendo aos propósitos de produzir e socializar prazer, através de um tácito pacto social de invisibilização do preconceito racial. 
Assim, o discurso jocoso da piada racista acaba por tornar-se um lugar da transgressão institucionalizada, onde o comportamento racial regido por um zeloso controle do politicamente correto é subliminarmente contradito. Dessa maneira, percorre-se um caminho inverso ao disciplinamento ensinado às crianças desde a tenra idade.

Embora tenha fornecido as bases teóricas para a lógica explicativa aqui adotada, o pensamento psicanalítico de Sigmund Freud (1905/1980) mostrou-se insuficientemente aparelhado para permitir uma análise que ultrapassasse a dimensão individual. Apesar de seus insights teóricos em outras direções, Freud conservou sua atenção em uma perspectiva eminentemente individual.

Por isso, a teoria psicanalítica de grupo de René Kaës serviu de suporte teórico central para a nossa discussão. A argumentação utilizada se desdobrou, preferencialmente, em torno dos conceitos de transmissão e grupalidade psíquica, aliança inconsciente e das categorias do intermediário e do negativo. Uma característica integradora de toda essa linha reflexiva está em buscar permanentemente a interseção entre realidades individuais e sociais para a compreensão do estilo sutil de manifestação do preconceito racial contra o negro no Brasil.

Em relação ao pensamento freudiano, em particular, a novidade contida na perspectiva psicanalítica de Kaës consiste em estudar seriamente a hipótese de que o inconsciente não mais pertença unicamente ao espaço intrapsíquico, além de procurar torná-lo passível de uma apreensão metodológica apropriada. Diferentemente da psicanálise freudiana, Kaës considera uma outra fonte de determinação na constituição do sujeito do inconsciente e dos efeitos de subjetividade, que, engendrados na intersubjetividade, dela resultam.

Dessa forma, o grupo é uma realidade psíquica específica, regida por determinações e processos próprios que produzem um trabalho psíquico, eminentemente de grupo. Para assumir tal formulação é necessária a construção de um referencial conceitual compatível, que forneça conceitos capazes de apreender 0 trabalho psíquico propriamente grupal. Kaës destacou certos tipos de formações psíquicas grupais, de estrutura e efeitos semelhantes às formações de compromissos. ${ }^{3}$ Essa linha investigativa abre brechas teóricas que permitem a análise sobre o nível de entrelaçamento intersubjetivo, advindo das negociações do inconsciente para produzir novas modalidades de formação de compromisso, como o riso e a piada racista - que encobrem o preconceito racial latente. Com isto, fornece pistas para a compreensão de como ocorre e se mantém o hábito de lazer de grupos, no Brasil, para contar e rir de piadas racistas. Além disso, ajuda a compreender como esse fenômeno integra um mecanismo de defesa 
de grupo que, inconscientemente selecionado, mascara a manifestação do preconceito racial contra os negros.

De acordo com Kaës et al. (2001, 2005), o tema da transmissão psíquica foi o responsável, nos escritos de Freud, pelo deslocamento da tópica do Individual do Inconsciente em direção a uma tópica intersubjetiva. A questão da transmissão se define, sobretudo, em torno da transmissão do Inconsciente, de suas formações e processos, pois "aquilo que se transmite são, essencialmente, configurações de objetos psíquicos, isto é, objetos munidos de seus vínculos com aqueles que precedem cada sujeito" (KAËS, 2005, p.128). Não apenas se transmitem ideais, mecanismos de defesa neuróticos e identificações, ou seja, o que assegura, pelo lado positivo, a continuidade e manutenção dos liames intersubjetivos. Essas configurações de objetos de transmissão incluem o "negativo". Transmite-se, também, a falta, a ruptura, a falha. Como sintetiza Kaës (2005):

\begin{abstract}
A problemática da transmissão não se organiza mais somente como a dos significantes e dos desejos pré-formados e deformados que nos precedem, mas como a dos significantes gelados, enigmáticos, brutos: sobre os quais não foi feito um trabalho de simbolização (p.129).
\end{abstract}

$\mathrm{Na}$ esteira dessa leitura, poderíamos inscrever a transmissão entre gerações e entre membros de uma mesma geração, do significativo silêncio sobre o racismo brasileiro (BENTO, 2002). Por ser percebido como uma falsa questão, o tema do preconceito racial, no Brasil, jamais emergiu como objeto de uma séria discussão. Pelo menos até bem pouco tempo atrás, preferiu-se sempre integrar a questão das relações raciais à esfera mais ampla da cultura, na qual outros elementos peculiares à nossa brasilidade, como a miscigenação racial, são celebrados (FREYRE, 1990). Mas esse expressivo silêncio sobre o tema, símbolo de um aparente gesto de "deixá-lo de lado", remete a negociações inconscientes permanentes para mantê-lo, que denotam, em última instância, sua centralidade na organização psíquica individual e intersubjetiva dos brasileiros.

Segundo Kaës, na obra Totem e tabu, publicada em 1913, Freud (1980) construiu a hipótese segundo a qual a condição possível para a existência de uma psicologia coletiva ou de massa está fundada na idéia de continuidade da vida psíquica, que ultrapassa as interrupções causadas pelo desaparecimento das vidas individuais. Do contrário, cada indivíduo estaria obrigado a recomeçar seu aprendizado da vida. Portanto, para Freud não há processo psíquico que possa ser suprimido de uma geração por outra geração seguinte. Mesmo reprimidos, tais 
conteúdos psíquicos são transmitidos através de um substituto, um traço, um resíduo de uma falta, de algo que não se realizou, tal como um recalcamento coletivo, até adquirir significado para um sujeito individual em uma geração vindoura (KAËS, 1997; KAËS; FAIMBERG; ENRIQUEZ; BARANES, 2001).

A hipótese de um apparat zu deuten ${ }^{4}$ constitui a resposta de Freud para a questão de como se daria a transmissão dos estados psíquicos. Para Freud (1913/1980), essa hipótese é oportuna, já que as vias da comunicação direta e da tradição parecem insuficientes para explicar a transmissão. Não se trata de uma herança passiva, uma vez que a herança das disposições psíquicas necessita da estimulação de acontecimentos da vida do indivíduo para ser despertada.

Em Sobre o narcisismo: uma introdução (1914/1980), Freud faz uma clara alusão ao processo pelo qual os pais transferem para os filhos e neles depositam a esperança de realização dos seus desejos não realizados. Nesse caso, a transmissão é feita negativamente, a partir de uma falta. A problemática do narcisismo traduzida numa divisão do sujeito do inconsciente entre duas possibilidades: ser um fim para si mesmo ou ser membro de uma cadeia intersubjetiva - à qual está ligado independentemente de sua vontade. Vista dessa maneira, a problemática do narcisismo está na raiz da questão da transmissão entre as gerações e através delas. Apoiado nestas leituras, Kaës (1997) afirma:

\begin{abstract}
Nascemos para o mundo já como membros de um grupo, ele próprio encaixado em outros grupos e com eles conectado. Nascemos elos no mundo, herdeiros, servidores e beneficiários de uma subjetividade que nos precedem e de que nos tornamos contemporâneos: seus discursos, sonhos, seus recalcados que herdamos, a que servimos e de que nos servimos, fazem de cada um de nós os sujeitos do inconsciente submetidos a esses conjuntos, partes constituídas e constituintes desses conjuntos (p.106).
\end{abstract}

Esta dupla condição do sujeito, de servidor e de beneficiário, faz alusão à reciprocidade de serviços vitais que trocam entre si indivíduo e espécie, sujeito e conjunto. Esta é a condição para ser considerado o sujeito do inconsciente, estar enredado na malha de transferência e entrelaçamento de matéria psíquica, comum ao sujeito singular e aos conjuntos que o constituem.

Nesse tipo de análise, um dos processos centrais de transmissão psíquica é constituído pelas alianças inconscientes. Através do conceito de aliança inconsciente, Käes explica uma espécie de pacto inconsciente, estabelecido intersubjetivamente entre os integrantes de um grupo, 
sincronicamente, e entre várias gerações, diacronicamente. Tal pacto é estabelecido para comunicar um interdito psíquico, algo indesejado que foi transmitido, uma falta que, nesse caso, pode significar um racismo latente, negado e não representado, mas sentido. Formalmente, para Kaës (2005), as alianças inconscientes designam:

\begin{abstract}
Uma formação psíquica intersubjetiva construída pelos sujeitos de um vínculo para reforçar, em cada um deles, certos processos, certas funções ou certas estruturas vindas do recalque, ou da recusa, ou do desmentido e da qual eles obtêm um benefício, tal que, o vínculo que os liga, adquire para sua vida psíquica, um valor decisivo (p.133).
\end{abstract}

Trata-se de um acordo inconsciente sobre o inconsciente. Um tipo de socialidade, estabelecida a partir de um pacto denegativo (operações de recalque, de denegação, de recusa, de desmentido, de rejeição). Esse pacto denegativo é produzido inconscientemente, para assegurar sua continuidade através da manutenção de certos benefícios e interesses advindos de tal configuração vincular.

Kaës chama a atenção para as diferenças que existem entre as várias relações vinculares postas em ação pelas alianças inconscientes. De acordo com o autor, o pacto denegativo emerge como contraponto e complemento ao contrato narcísico. A função do contrato narcísico é acentuar a missão do sujeito de ser, ao mesmo tempo, um fim para si mesmo e um elo que assegura a continuidade do conjunto social através das gerações. Na raiz desse contrato reside a relação entre sujeito e sociedade. Por sua vez, o pacto é originário de uma paz estabelecida arbitrariamente, sendo portador de uma dupla polaridade: de organização do vínculo no conjunto social e de defesa. Como diz o próprio Käes,

Cada conjunto particular organiza-se positivamente sobre investimentos mútuos, sobre identificações comuns, sobre uma comunidade de ideais e de crenças, sobre um contrato narcísico, sobre modalidades toleráveis de realizações de desejos... Cada conjunto organiza-se, também, negativamente, sobre uma comunidade de renúncias e de sacrifícios, sobre extinções, rejeições e recalcamentos, sobre um 'deixado de lado' e sobre restos. O pacto denegativo contribui para essa dupla organização. Ele cria no conjunto do não-significável, do nãotransformável: zonas de silêncio, bolsos de intoxicação, espaços latas de lixo ou linhas de fuga que mantêm o sujeito estranho à sua própria história. Nos casais, nas famílias, nos grupos e nas instituições, as alianças, contratos e pactos inconscientes sustentam especialmente o destino do recalcamento e da repetição (1997, p. 265). 
Esse tipo de vínculo negativo remete a aspectos latentes no comportamento de brasileiros que não se consideram racistas, mas expressam seu racismo através de risos e relatos de piadas racistas, quando reunidos num espaço de lazer. O que é mais estranho é que esse tipo de comportamento racista não interfere na sua inatacável reputação de democratas raciais. Riem, comem, bebem, se divertem e relaxam, sem nada saberem sobre o próprio racismo. Na realidade, as alianças inconscientes têm, como condição de manutenção, o próprio desconhecimento dos desejos dos seus pactuantes.

A renúncia inconsciente do preconceito aberto e ostensivo, de deixar de lado o próprio preconceito racial, parece derivar de uma aliança inconsciente, que permitiu a transgressão através de um riso partilhado e repetido, suscitado pelo relato da piada racista. A piada e o riso em seu entorno filtram a virulência do preconceito e o substituem, atenuando sua imagem até a sua completa diluição, pelo menos do ponto de vista dos personagens que protagonizam essa cena social. A renúncia, inconsciente, efetiva o vínculo intersubjetivo e o mantém. Nesta configuração, o preconceito racial é preservado e remetido, defensivamente, a uma zona de silêncio. Na verdade, a renúncia intersubjetiva ou social ocorre para que o preconceito racial, invisível, já que inscrito em outra ordem de realidade psíquica, seja garantido. Esse deslocamento ou recalcamento do conteúdo do objeto parece se dar através de um mecanismo coletivo.

Em Freud, o recalcamento consiste num processo individual, de caráter intrapsíquico. No entanto, seguindo a linha investigativa proposta por Kaës, é possível considerar uma outra modalidade de recalcamento, posto em ação com as alianças inconscientes. As alianças supõem, simultaneamente, as idéias de obrigação e de sujeição, que atendem a uma função recalcante e mesmo sobrerecalcante. É como se constituíssem uma espécie de redobramento do recalque, uma vez que se manifestam não apenas sobre os conteúdos inconscientes, mas sobre a própria aliança.

Com essas reformulações, Kaës (1997) está propondo, na verdade, a possibilidade de uma produção grupal de recalcamento. Essa produção tem uma função co-recalcadora própria, alicerçada, portanto, numa condição intersubjetiva.

A partir dos dados clínicos engendrados em grupo, o autor formula a existência de formas de retorno do recalcado, como, por exemplo, uma produção grupal dos sintomas, mantidos intersubjetivamente por uma economia e uma lógica grupais. Outras formas de retorno do recalcado, como a piada racista, uma cristalização social do deboche racial, podem 
ser, também, tributárias dessa mesma lógica e dessa mesma economia grupal.

$\mathrm{Na}$ verdade, Kaës (1997) propõe as bases de uma metapsicologia intersubjetiva. Os princípios dessa metapsicologia se organizam em torno do pressuposto de que o inconsciente é engendrado em uma realidade psíquica que vai além do meramente individual. Com efeito, nesse tipo de instância psíquica, o inconsciente trabalha e é trabalhado a partir de uma lógica própria, de caráter grupal.

O referido autor identifica uma categoria de organização psíquica dos grupos, que se caracteriza pelas formações e processos que são inscritos na cultura. Tais formações e processos são constituídos pelas contribuições do discurso comum, partilhado pelos sujeitos dos grupos. A partir do seu próprio discurso associativo, os sujeitos modificam e integram os enunciados postos em grupo. A consequência disso é a formação de um estilo de pensamento que adquire características e funções grupais. Segundo Kaës, esses processos e formações psíquicas equivalem ao Apparat zu deuten de Freud, um aparelho inconsciente dos sujeitos para interpretar e produzir significados. Esse aparelho inconsciente de transmissão integra a psique coletiva e constitui seu substituto no sujeito singular, ou seja, constitui aquilo que, no inconsciente individual, é coletivo e impessoal. A distinção em relação ao pensamento de Freud consiste em que, aqui, essa atividade desempenha uma função coletiva. Não é possível, portanto, pensar tal hipótese a não ser a partir do estreitamento das dimensões intrapsíquicas e intersubjetivas. Nas palavras do próprio Käes (1997),

\begin{abstract}
O objetivo dessa metapsicologia intersubjetiva seria articular as relações entre o duplo limite constitutivo do espaço psíquico: o limite intrapsíquico entre $o$ Inconsciente e $o$ Préconsciente/Consciente; o limite interpsíquico entre o sujeito e o não-sujeito. O principal problema é explicar esses dois fatos: que os dois limites cruzam-se dentro e fora de cada sujeito e que a textura psíquica da intersubjetividade é a condição do Sujeito do Inconsciente (p.247).
\end{abstract}

Sua teoria prevê a categoria do intermediário, para tratar da articulação entre as formações específicas, produzidas em grupo, e as formações psíquicas singulares. Tal conceito desempenha a função de ponte entre duas ordens de realidades psíquicas heterogêneas, não redutíveis uma à outra, em razão de serem, as duas, regidas por lógicas distintas. Tratase de uma categoria erigida para promover o "enodamento" entre a ordem própria do social e a ordem própria do espaço psíquico, sem comprometer a integridade de cada um dos respectivos espaços. 
À categoria de intermediário são atribuídas, de um modo geral, três funções: (1) efetivar as ligações entre elementos de um sistema; (2) estabelecer ou restabelecer uma continuidade entre elementos distantes; e (3) mediar a relação de elementos em conflito. A partir dessas características, Kaës (2005) sugere que a categoria do intermediário reverte uma condição de ruptura e conflito num potencial criador: de vida psíquica, de vida relacional e de vida cultural. A piada pode ser vista como uma resultante cultural objetiva do pacto racista, o riso, sua garantia contingencial de repetição, uma vez que se trata de uma dinâmica prazerosa operada a partir de um relaxamento psíquico e social.

De acordo com Käes, a categoria do intermediário é um conceito que pode ser inferido, ou melhor, construído, a partir do conjunto de toda a obra freudiana, mesmo que tal conceito não tenha sido abordado explicitamente. Por exemplo, na obra freudiana A interpretação dos sonhos (1901/1980), de modo especial, a categoria do intermediário adquire uma importância central, com o sonho passando a ser compreendido como o reino intermediário, no limite entre o sono e o estado de vigília. No sonho, é estabelecido um vínculo entre os conteúdos latentes e os conteúdos manifestos. Analogamente, na formulação da segunda tópica, o ego é visto como uma instância de regulação e de defesa, um ser-fronteira e um ser-de-fronteira. Em Psicologia de grupos e análise do Ego (1921/1980), Freud destaca o seu papel mediador entre líder e massa, ilustrado na figura de Moisés, o intermediário entre Jeová e seu povo. Em Totem e Tabu (1913/1980), numa abordagem mais cultural, Freud trata do pacto, selado pelos irmãos em relação ao assassinato do pai original, como uma formação intermediária, fundamento da organização social estruturada sob algumas restrições sociais. Mantendo o mesmo enfoque na cultura, em Mal-estar da Civilização (1930/1980) Freud aponta a renúncia aos ditames da pulsão, como condição necessária para a existência do vínculo social, das produções culturais e da própria civilização, destacando, assim, a natureza ambivalente dos processos intermediários.

Numa perspectiva mais recente, o conceito de intermediário adquire vigor em meio à crise da sociedade pós-moderna. A sociedade pósmoderna é caracterizada por um processo ininterrupto de rupturas, descontinuidades e fragmentações internas, na economia, na tecnologia, na cultura e na vida cotidiana, que acabam por produzir um sentimento de incerteza generalizado. Existe, também, o declínio das identidades culturais de sexualidade, etnia, raça, nacionalidade e classe, que nas sociedades tradicionais serviam de referência para o enquadramento 
social dos indivíduos. Todas essas características integram esse processo mais amplo de mudanças nas estruturas centrais da sociedade contemporânea, constituindo a chamada "crise de identidade".

Para Kaës, as perturbações e sofrimento psíquicos são derivados das dificuldades em lidar com a questão das rupturas, da falta de continuidades, das ambivalências e das indefinições identitárias, inerentes ao nosso tempo e que se manifestam no âmbito psíquico, social e cultural. Essas dificuldades podem ser decorrentes de falhas nas funções intermediárias. A própria cultura pode ser vista como um processo intermediário, através do qual é estabelecida uma conexão entre o mundo interno do sujeito psíquico e a realidade dos signos, dos sentidos e rituais construídos e partilhados socialmente.

$\mathrm{Na}$ história do racismo brasileiro, identificamos outros momentos significativos de indefinições sociais, possivelmente geradores de grandes descontinuidades. Um exemplo, particularmente esclarecedor, nesse sentido, aconteceu quando da instituição da Lei Áurea, momento no qual foi abolida a escravidão dos negros, do ponto de vista jurídico, sem uma coincidente acomodação psíquica, social e cultural da idéia de igualdade social.

Em sua dissertação de mestrado, intitulada A Piada: discurso sutil de exclusão (1994), Dagoberto José Fonseca sugere que, provavelmente, foi nesse contexto que tiveram início a produção e transmissão de piadas racistas. Esse autor considerou que, durante a escravidão, praticamente inexistiam piadas com conteúdos ofensivos direcionados aos negros, uma vez que eles eram vistos como mercadorias, destituídos, portanto, de expressão na esfera social.

No entanto, antes da abolição da escravatura, vigoravam leis rígidas que promoviam uma clara diferenciação social, fundada no conceito de raça. Depois deste fato histórico, que instituiu uma ampla afirmação da igualdade de direitos entre os indivíduos, independentes da cor, outros recursos tiveram que ser utilizados para restabelecer as posições sociais originais.

A esse respeito, deve-se considerar a leitura do antropólogo Roberto DaMatta (1987, 1997, 2001), sobre a ambiguidade do sistema social brasileiro. Para esse autor, o sistema social brasileiro oculta, através de um discurso igualitário e conciliador, um sistema fortemente hierarquizado. A despeito das determinações legais, esse sistema hierarquizado parece preservar, através da adoção de novos e sutis mecanismos simbólicos, a disposição diferenciada dos lugares sociais. Mesmo considerando esse mecanismo compensatório previsto por DaMatta, sugerimos que o descompasso social gerado pela intervenção jurídica fragilizou, de certo modo, a solidez e estabilidade de suas 
configurações identitárias. Ou seja, o estado de descontinuidade posto pela inédita situação pós-escravatura passou a requerer, a cada momento, todo um aparato simbólico compensatório que, na nossa leitura, se mostrou insuficiente. Essa necessidade compensatória, frequente e intensa, acabou por engendrar uma aliança firmada intersubjetivamente, em um nível inconsciente, com função mediadora de regulação psíquica dos grupos sociais e dos indivíduos. Tal pacto foi selado através de sucessivas gerações e é ainda negociado, a cada encontro social, por intermédio do riso, cujo poder comunicante engendra um liame emocional no interior dos grupos.

Assim como toda produção do inconsciente, incluindo o sonho, o sintoma e o lapso, entre outros, o riso ou chiste desempenha uma função intermediária, de ligação e de compromisso. Ele articula dois níveis distintos de realidade, de forma a garantir sua continuidade e evitar ou, pelo menos, reduzir o sofrimento psíquico causado por possíveis falhas nos sistemas intermediários.

A suposição do presente artigo é a de que as piadas racistas e o riso advindo dessa situação, nos círculos de amigos, em um ambiente de descontração, representam uma formação intermediária entre duas situações identitárias diferentes. O riso, expresso coletivamente, expressa uma posição que encobre um racismo negado, mas existente e mal resolvido e, por isso, recorrente entre muitos dos brasileiros. Ele simboliza um pacto inconsciente, selado sobre uma problemática vivenciada historicamente, que vem atravessando as gerações. Ele emerge para solucionar o problema da descontinuidade do racismo para um racismo latente, expresso como não-racismo, ou não-expresso. A abolição da escravatura no Brasil, associada a uma auto-imagem de país sincrético e democrático, remeteu para o riso, suscitado pela piada, grande parte do drama concernente às relações raciais brasileiras. Assim, o riso se torna uma espécie de substituto simbólico, para reduzir o conflito interno entre duas tendências existentes a partir de então: a dos racistas e a dos democratas raciais.

Através da categoria de intermediário, desloca-se o conflito, também de caráter intersubjetivo, pelo menos em nível de sua resolução, para uma dimensão inconsciente, longe das censuras sociais e pessoais. Esse trabalho é realizado com maestria pelo riso, uma vez que sua função intermediária o coloca na fronteira entre seriedade e brincadeira, dois níveis heterogêneos de realidade, o que permite um curioso jogo de invisibilização e de irrupções inconscientes do preconceito racial. É nessa medida que, enquanto objeto cultural, a piada articula, de modo lúdico, as ligações intrapsíquicas e as estruturas de vínculo social. 
Tais espaços lúdicos ganham sustentação no vínculo intersubjetivo que o riso social e a piada põem em funcionamento. Trata-se de um ritual crucial na perpetuação do preconceito racial, que ocorre através do estabelecimento de contratos inconscientes. Para que se apreenda a formação e o significado desse vínculo intersubjetivo, é preciso que, na perspectiva diacrônica, se estabeleça um corte sincrônico, mais ou menos estável, que serve de pano de fundo necessário para a organização dos grupos. Nessa situação, o vínculo intersubjetivo aparece como fortuito, mas é suficiente para assegurar certas funções vitais de regulação psíquica.

A dinâmica possui uma lógica: rir de alguém significa rebaixá-lo, significa remover a aura de seriedade que equilibra as relações sociais de igualdade. No Brasil, para além do comportamento regulado pela ação da lei, se desenvolveu uma prática social de somente falar da questão racial, sem auto-censura e censura social, através da brincadeira. Tal como estamos propondo neste estudo, trata-se de uma manobra muitas vezes inconsciente, para lidar com problemas de identidade e parece envolver sofrimento psíquico. Isso porque implica em um conflito identitário, não apenas individual, mas também coletivo, uma vez que evidencia questões culturais pertinentes ao nosso país, à nossa brasilidade.

Desse maneira, paliativos catárticos, de ocorrência recorrente, tomaram lugar na cena brasileira, de tal modo que nos "acostumamos" a conviver, de forma pacífica, com essa aparente inofensiva saída para nossos mal-estares. Rebaixa-se, humilha-se, vira-se a ética de ponta a cabeça, mas libera-se o ódio represado. O equilíbrio psíquico é restaurado, a sanidade da nossa cultura é finalmente salva, pelo menos temporariamente, até um próximo encontro social. Não há consciência sobre esse jogo, suas regras são estabelecidas na obscura ação das alianças inconscientes. E o riso é o elemento intermediário que celebra tal "solução".

\section{Conclusão}

A categoria do intermediário não é, contudo, uma garantia absoluta de equilíbrio psíquico. Sua natureza é frágil e dela se exige, permanentemente, um trabalho psíquico para fazer frente ao trabalho da cultura. Aqui, poderíamos interpor o movimento próprio da história, com suas questões políticas, sociais e culturais, em constante mutação. É esse movimento constante que enfraquece certas representações identitárias, motivadas por novos cenários sociais, fragilizando a qualidade dos pactos selados no seu interior. Exemplo disso é o programa de política de ações afirmativas que, recentemente, vem 
ocupando a agenda política no Brasil. Nesse contexto, a discussão sobre as ações afirmativas para os afro-descendentes tem se reduzido, quase exclusivamente, à questão de cotas numéricas, para garantir a inclusão de membros de grupos desfavorecidos em determinados espaços. Entretanto, independente do seu mérito, o debate tem servido para mobilizar a atenção e os sentimentos ambivalentes dos brasileiros. Trazer o tema das relações raciais para o centro do debate e discutí-lo em outros termos, às claras, deverá interferir, de forma salutar, nas composições inconscientes. Em última instância, o que o entrelaçamento de tais eventos atesta é o nível de envolvimento do inconsciente, de seus processos e de suas estratégias de irrupção e adaptação, na malha do social.

\section{Referências Bibliográficas}

ALBERTI, V. O Riso e o risível na história do pensamento. 2 ed., Rio de Janeiro: Jorge Zahar Ed., 2002.

BENTO, M. A. Branqueamento e branquitude no Brasil. In: CARONE, I.; (Orgs.). Psicologia social do racismo. Petrópolis, Rio de Janeiro: Vozes, 2002. p. 25-57.

CAMINO, L.; SILVA, P.; MACHADO, A.; PEREIRA, C. A Face oculta do racismo no Brasil: Uma análise psicossociológica. Revista de psicologia política, v.1, n.1, p. 13-36, 2001.

DAHIA, S. Riso, preconceito racial e aliança inconsciente: uma leitura possível. 2007. Tese (Doutorado em Sociologia), 121 p. Universidade Federal da Paraíba, João Pessoa.

DAMATTA, R. Relativizando: uma introdução à antropologia social. Rio de Janeiro: Rocco, 1987.

Carnavais, malandros e heróis: para uma sociologia do dilema brasileiro. 6 ed. Rio de Janeiro: Rocco, 1997.

O que faz o brasil, Brasil? 12ed., Rio de Janeiro: Rocco, 2001.

FAZZI, R. C. O drama racial de crianças brasileiras: socialização entres pares e preconceito. Belo Horizonte: Autêntica, 2004.

FONSECA, D. J. A Piada: discurso sutil de exclusão, um estudo do risível no "racismo à brasileira". 1994. Dissertação (Mestrado em Ciências Sociais), 298 p. Pontifícia Universidade Católica, São Paulo.

FREYRE, G. Casa-grande e senzala. 27 ed., Rio de Janeiro: Record, 1990.

FREUD, S. A interpretação dos sonhos. Edição Standard Brasileira das Obras completas. (E.S.B.), v. IV e V, Rio de Janeiro: Imago, $1900 / 1980$. 
. Os chistes e sua relação com o inconsciente. Edição Standard Brasileira das Obras completas. (E.S.B.), v. VIII, Rio de Janeiro: Imago, 1905/1980.

. Totem e tabu. Edição Standard Brasileira das Obras completas. (E.S.B.), v. XIII, Rio de Janeiro: Imago, 1913/1980.

. Sobre o narcisismo: uma introdução. Edição Standard Brasileira

das Obras completas. (E.S.B.), v. XIV, Rio de Janeiro: Imago, 1914/1980.

. Psicologia de grupo e a análise do ego. Edição Standard Brasileira das Obras completas. (E.S.B.), v. XVIII, Rio de Janeiro: Imago, $1921 / 1980$.

. O Mal-estar na civilização. Edição Standard Brasileira das Obras completas. (E.S.B.), v.XXI, Rio de Janeiro: Imago, 1930/1980.

KAËS, R. O grupo e o sujeito do grupo: elementos para uma teoria psicanalítica do grupo. São Paulo: Casa do Psicólogo, 1997.

KAËS, R.; FAIMBERG, H.; ENRIQUEZ, M.; BARANES, J. J. Transmissão da vida psíquica entre gerações. São Paulo: Casa do Psicólogo, 2001.

KAËS, R. Os Espaços psíquicos comuns e partilhados: transmissão e negatividade. São Paulo: Casa do Psicólogo, 2005, (Col. Psicologia Social, Inconsciente e Cultura, coordenadora: Maria Inês Assumpção Fernandes).

LAPLANCHE, J; PONTALIS, J. B. Vocabulário da psicanálise. 4 ed., São Paulo: Martins Fontes, 2001.

MINOIS, G. História do riso e do escárnio. São Paulo: Editora UNESP, 2003.

NOGUEIRA, O. Tanto preto quanto branco: estudo de relações raciais. São Paulo: T. A. Queiroz, 1985.

PEREIRA, C.; TORRES, A. R.; ALMEIDA, S. T. Um estudo do preconceito na perspectiva das representações sociais: análise da influência de um discurso justificador da discriminação no preconceito racial. Psicologia: reflexão e crítica, v.16, n.1, p. 95-107, jan. 2003.

VALA, J. Novos racismos: perspectivas comparativas. Oeiras: Celta Editora, 1999.

\section{Endereço para correspondência}

Sandra Leal de Melo Dahia

Departamento de Psicologia Centro de Ciências Humanas, Letras e Artes Universidade Federal da Paraíba, Campus I, Conjunto Humanístico, Bloco IV, Cidade Universitária João Pessoa, CEP 58.051 -970, João Pessoa - PA, Brasil

Endereço eletrônico: sandradahia@yahoo.com.br

Recebido em: 27/09/2009

Aceito para publicação em: 13/01/2010 
Acompanhamento do processo editorial: Ana Maria Lopez Calvo de Feijoo

\section{Notas}

${ }^{1}$ Este é um cenário que começa a sofrer mudanças, em função do crescente controle da sociedade, no sentido de estabelecer práticas politicamente corretas

2 Talvez esta concepção remonte ao pensamento clássico sobre o riso, visto como essencialmente contrário ao sério, ao verdadeiro. Ver Alberti (2002) e Minois (2003).

${ }^{3}$ De acordo com Laplanche e Pontalis, formação de compromisso se refere "à forma que o recalcado assume para ser admitido no consciente, retornando no sintoma, no sonho (...), em qualquer produção do inconsciente. As representações recalcadas são então deformadas pela defesa, ao ponto de serem irreconhecíveis" (2001, p.198).

${ }^{4}$ Aparellho para interpretar (KAËS, 2005, p.68). 